\title{
The gr/gr deletion(s): a new genetic test in male infertility?
}

Y chromosome microdeletions are the most frequent genetic cause of severe oligozoospermia $(<5$ million spermatozoa $/ \mathrm{ml}$ ) and azoospermia (absence of spermatozoa in the ejaculate). ${ }^{1}$ Microdeletions associated with infertility occur in specific regions of the long arm of the $\mathrm{Y}$ chromosome, called azoospermia factor (AZF) regions. ${ }^{2}{ }^{3}$ In 1996, three types of AZF deletion (AZFa, AZFb, and AZFc) were described by Vogt et al; however, after the complete physical map and sequence of the AZFb and AZFc regions was produced, ${ }^{4}$ it became evident that the AZFb and AZFC intervals partially overlap. ${ }^{5}$ The $\mathrm{Y}$ chromosome is extremely rich in repetitive sequences, organised in amplicons. ${ }^{6}$ Ampliconic sequences are characterised by sequence pairs showing nearly complete $(>99.9 \%)$ nucleotide identity, organised in massive palindromes. These repeated sequences may undergo genetic exchange through gene conversionthat is, non-reciprocal transfer of sequence information occurring between duplicated sequences within the chromosome, a process that could account for the $>99.9 \%$ nucleotide identity between the arms of a palindrome. Although this mechanism may serve to preserve $\mathrm{Y}$ chromosome genes from the gradual accumulation of deleterious mutations and thus prolong their genetic fitness, ${ }^{6}$ this peculiar organisation also provides the structural basis for deletions and rearrangements.

The classical AZFC deletion, which removes $3.5 \mathrm{Mb}$ between the b2/b4 amplicons, is the most frequent type of deletion. Taking into consideration the $\mathrm{Y}$ chromosome structure and the suggested deletion mechanism, a number of other possible partial deletions have been proposed in both the $\mathrm{AZFb}$ and $\mathrm{AZFC}$ regions. ${ }^{78}$ The frequency and the pathological significance of these partial deletions is not yet clear, although recently a partial deletion termed gr/gr has been described specifically in infertile men with varying degrees of spermatogenic failure. ${ }^{9}{ }^{10}$ This deletion removes half the AZFc gene content, including two copies of the major AZFc candidate gene called DAZ. ${ }^{11}$ Another deletion, named $\mathrm{b} 2 / \mathrm{b}^{12}$ or $\mathrm{u} 3-\mathrm{gr} / \mathrm{gr}^{13}$ or $\mathrm{gl} / \mathrm{g} 3,{ }^{14}$ which removes a similar quantity of AZFc genes, seems to have no effect on fertility status in association with a certain $\mathrm{Y}$ chromosome background commonly present in northern Eurasian populations (Y haplogroup N). ${ }^{12}{ }^{13}$ A similar conclusion can also be drawn for the gr/gr deletion found in association with Hgr D2b, which is present in $20 \%$ of Japanese men. One of the possible explanations for the heterogeneous phenotype observed in association with complete and partial AZFc deletions is that polymorphisms or mutations are present in the autosomal homologue of $D A Z, D A Z L .{ }^{15}$ Indeed, the finding that the human $D A Z$ transgene is able to partially rescue the spermatogenic failure of mice homozygous for a null allele of Dazl $^{16}$ suggests a possible interplay between DAZL and DAZ in humans. In the case of partial AZFc deletions, we can also speculate that the type and number of missing gene copies or other unknown Y chromosome related factors (for example duplications or beneficial mutations in other parts of the $\mathrm{Y}$ chromosome) may also influence the phenotype.

\section{Key points}

- Deletion of the AZFc region of the $Y$ chromosome is the most frequent molecular genetic cause of oligo/ azoospermia. Within this region, partial deletions have been recently described, including the $\mathrm{gr} / \mathrm{gr}$ deletion.

- A direct aetiopathogenic role has been suggested for the $\mathrm{gr} / \mathrm{gr}$ deletion as it was absent in normozoospermic but present in oligospermic men.

- We studied a group of normospermic $(n=189)$ and oligo/azoospermic $(n=150)$ men using a sequence tagged site (STS) + / - method. To gain insight into the molecular basis of the heterogeneous phenotype observed in men with the deletion we: (a) defined the type of DAZ and CDY 1 genes deleted and the $Y$ haplogroup, and (b) carried out a mutational screen of $D A Z L$, the autosomal homologue of DAZ.

- We found that: (a) partial AZFc deletions are not specific for spermatogenic failure, and (b) $\mathrm{gr} / \mathrm{gr}$ deletion can be considered as a risk factor because its frequency was significantly higher in the oligo/ azoospermic group (5.3\%) than in controls $10.5 \%$ ) $\mathrm{p}<0.012$.

- Gene specific analysis revealed three distinct deletion patterns, indicating that further combined studies based on gene copy and haplogroup analysis are likely to provide a means for the distinction between pathogenic and neutral (or compensated by other $Y$ factors) types of deletion.

The aims of this study were: $(a)$ to establish the clinical significance of partial AZFc deletions (that is, if any of them are specific for spermatogenic failure or can be considered a risk factor); and $(b)$ to gain insight through a combined approach (quantitative and qualitative analysis of $D A Z$ and $C D Y$, definition of $\mathrm{Y}$ chromosome haplogroup, and mutational analysis of DAZL in men with partial AZFc deletion) into the molecular basis of the heterogeneous phenotype described in men bearing partial AZFc deletions.

\section{MATERIALS AND METHODS \\ Subjects}

The study population consisted of 150 infertile patients (89 idiopathic and 61 with mild abnormal andrological findings: varicocele, monolateral cryptorchidism, recurrent infections) seeking complete andrological investigation for couple infertility at the Andrology Unit of the University Hospital Careggi in Florence, Italy, and 189 normospermic controls of

Abbreviations: $A Z F$, azoospermia factor; $S F V$, sequence family variant; SNV, single nucleotide variant; STS, sequence tagged site 
Italian origin. Cytogenetic analysis and $\mathrm{Y}$ chromosome microdeletion screening revelaed 46,XY karyotype and the absence of AZF microdeletions in all included patients. Samples were collected using approved protocols and the informed consent of all individuals was obtained.

\section{Screening for partial AZFc deletions}

We tested eight STSs, originally described by Repping et al ${ }^{9}$ : sY1291, sY1191, sY1161, sY1206, sY1201, sY142, sY1258, and sY1197. In addition, we tested our samples with a complementary set of primers, ol084/1085 and ol276/1277. ${ }^{13}$ We identified gr/gr deletion by the following STS results: sY1291 and o1084/85 negative; sY1161, sY1191, sY1206, sY1201, and ol276/1277 all positive (an example of a PCR duplex result is shown in fig 1 ). The $\mathrm{b} 2 / \mathrm{b} 3$ or $\mathrm{u} 3$-gr/gr deletion is characterised by the absence of the STS sY1191-o1276/1277 and the presence of the rest of the STS.

Qualitative and quantitative analysis for DAZ copy and CDYa/CDYb loss was performed according to Machev et al. ${ }^{13}$ For $D A Z$, we chose the sequence family variant (SFV) at STS sY587 in intron 10, which distinguishes $D A Z 1 / 2$ from DAZ3/4.

For CDYl we used a C/A SFV situated 7750 bp $5^{\prime}$ of the CDYl translation start codon (CDY7750). In order to quantify copy number we used a PCR based method described by Machev et al. ${ }^{16}$ The PCR products were separated on an automatic sequencer (LI-COR Gene ReadIR 4200), and quantification was performed by ONE-Dscan.

\section{Y chromosome haplotyping}

$\mathrm{Y}$ chromosome haplotyping was performed as previously published for the YAP, M9, SRY4064, and 92R7 polymorphisms. ${ }^{17}$ The Tat polymorphism ${ }^{18}$ was assayed by PCR digestion with primers ol489: atgtatatagtacgtctgtagg and ol490: gtaagcataattgagaaggtgcc (annealing $54^{\circ} \mathrm{C}$ ). The $12 \mathrm{f} 2$ assay was performed as a duplex with SRY primers 3'SRY15 and 3'SRY16 and thel2f2 primers $12 \mathrm{f} 2 \mathrm{D}$ and $12 \mathrm{f} 2 \mathrm{~F} .{ }^{17}$ These primer pairs were used at a concentration of $300 \mathrm{nmol} / \mathrm{l}$ for each $S R Y$ primer and $600 \mathrm{nmol} / \mathrm{l}$ for each $12 \mathrm{f} 2$ primer, and the annealing temperature used was $52^{\circ} \mathrm{C}$. Polymorphisms were visualised by restriction enzyme digest for M9 (HinfI), SRY4064 (BsrBI), Tat (HpyCH4IV), and 92R7 (HindIII).

All men were haplotyped for YAP, 12f2, and 92R7 polymorphisms (table 1), and individuals with partial AZF deletions were further genotyped with the Tat, M9, and SRY4064 SNPs, defining five haplogroups, $\mathrm{E}, \mathrm{J}$, and $\mathrm{K}(\mathrm{xN} 3, \mathrm{P})$, $\mathrm{N} 3$, and $\mathrm{P}$, and one paragroup $\mathrm{Y}^{*}(\mathrm{xD}, \mathrm{E}, \mathrm{J}, \mathrm{K})$.

\section{Statistical analysis}

Statistical analysis was performed using the statistical package SPSS for Windows (version 11; SPSS, Chicago, IL, USA). We tested the significance of the observed difference in the incidence of gr/gr deletion between our infertile and control populations using Fisher's exact test. Our null hypothesis was that incidence is the same in infertile and control populations. All variables were checked for normal distribution by Kolmogorov-Smirnov one sample test. For comparisons of means between groups of different genotypes, Student's $t$ test for independent samples, when normal distribution was observed, was applied. Logarithmic transformation of data was performed in order to normalise the distribution when the presence of $\log$ normal distribution was checked. Finally, in case of non-normalised distribution, the non-parametric MannWhitney $U$ test was applied to achieve the same objective. A $p$ value $<0.05$ was considered statistically significant for each test.

\section{RESULTS}

Frequency and type of partial AZFc deletions in patients and normospermic men

Based on the STS $+/-$ analysis $^{916}$ it was possible to distinguish between different types of partial deletions (fig 1). We found two types of partial AZFc deletions: the gr/gr (8/339) and the b2/b3 (3/339) deletion, whereas bl/b3 was absent in our study population.

The gr/gr and b2/b3 deletions were found in both the infertile and normospermic groups, although at different frequencies. The frequency of gr/gr deletions was significantly higher in the patient $(8 / 150 ; 5.3 \%)$ than in the normospermic group $(1 / 189 ; 0.5 \%)(p<0.012$; odds ratio (OR) 10,$16 ; 95 \%$ confidence interval (CI) 1.28 to 80.3 ). In contrast, the frequency of the less common b2/b3 (u3-gr/gr) deletion was not different between the two groups $(1.3 \% \vee 0.5 \%$; $=0.41)$.

\section{DAZ and CDY1 gene copy definition}

In order to further characterise the deletions, we defined the type of missing DAZ (DAZ1/DAZ2/DAZ3/DAZ4) and CDYI $(C D Y I a / C D Y I b)$ gene copies. In the gr/gr deletion group, we found three types of deletion pattern: DAZ1/DAZ2+CDY1a, $D A Z 3 / D A Z 4+C D Y 1 a$, and DAZ3/DAZ4+CDYIb (fig 2). In the b2/ b3 deletions group, we found two types of deletion pattern: $D A Z 3 / D A Z 4+C D Y 1 a$ and DAZ3/DAZ4+CDYlb. The presence of different gene copy deletions patterns (five combinations found in our study) indicates that each type of partial deletion may be further divided into subtypes, and although the number of gene copies removed is the same, the missing copy type is different.

Interestingly, DAZ1/DAZ2 and CDYla were deleted only in the patient group, whereas DAZ3/DAZ4 and CDYlb were deleted in both groups. However, the deletion of CDYla was not consistently associated with the absence of DAZ1/DAZ2 copies and thus can be deleted with either $D A Z$ gene pair. The absence of the $D A Z$ and $C D Y$ copies was further confirmed by a densitometric analysis, according to Machev et al. ${ }^{16}$ In all the gr/gr and b2/b3 deletion cases, we found a reduction of gene dosage for $D A Z$ and $C D Y 1$. We have therefore no case of b2/b4 duplication among the men with deletions.

\section{Genotype-phenotype association}

Both types of deletion were associated with a wide range of sperm count, from azoospermia to normozoospermia (table 1). Although the mean values of the three principal sperm parameters were lower in patients with gr/gr deletion than in patients without, the difference was not significant: $2.1 v 4.5$ million spermatozoa/ml for mean sperm concentration, $12.8 \% v 20.8 \%$ for sperm motility, and $11.6 \% v 15.3 \%$ for morphology. As CDYla deletion was a specific feature of the patient group, we calculated the frequency of gr/gr deletions with missing CDYla in both patients and controls; the difference between the two groups was highly significant $(p<0.003)$. It is therefore possible that only specific patterns of partial deletions are deleterious for spermatogenesis.

We also sequenced the entire coding sequence of $D A Z L$ to test whether allelic forms of DAZL might underlie the phenotypic variation associated with the partial deletions. We found no new mutations. Only one single nucleotide variant (SNV) was found, at nucleotide position $260 .{ }^{19}$ Two patients were heterozygous for this SNV; however, its incidence in normospermic and infertile men is similar ${ }^{19}$ and thus it is unlikely to have any significant effect on the phenotype.

\section{Genotype-Y chromosome haplogroup and phenotype relationship}

Recent studies reported that b2/b3 (u3-gr/gr or gl/g3) deletions primarily arise in one family of closely related 

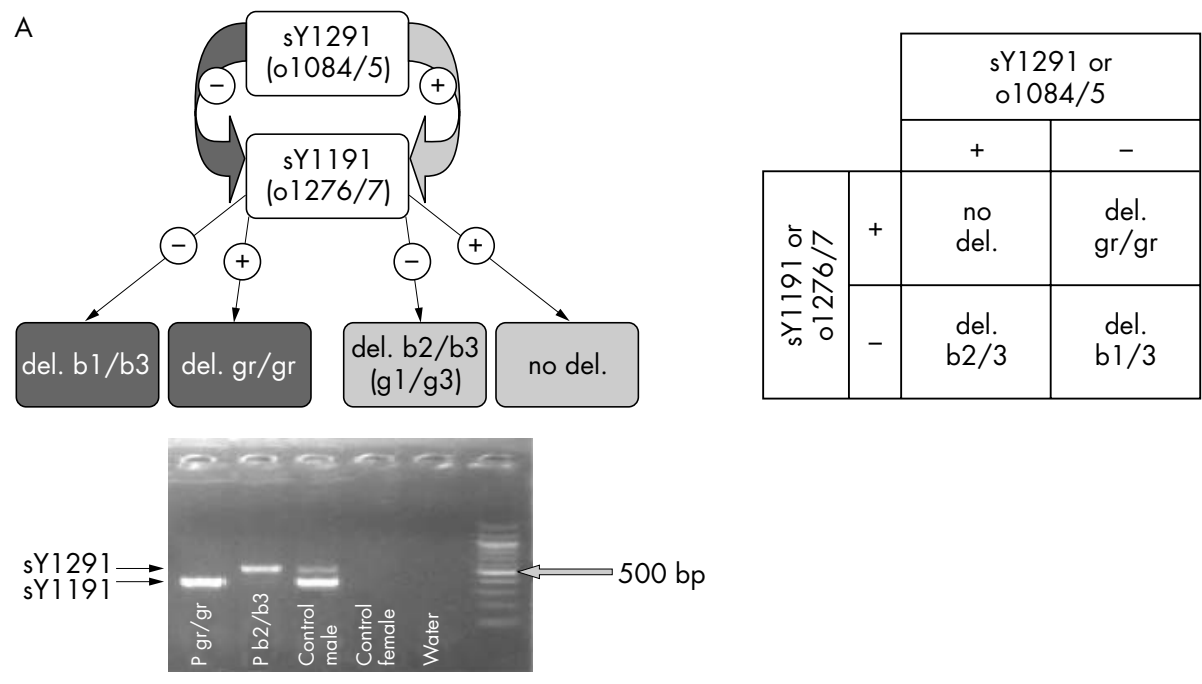

B

\begin{tabular}{|c|c|c|c|c|c|c|c|}
\hline & sY1258 & sy1 $161(\times 2)$ & sY1197 & sY1191 & sY1291 & sY1206 (×2) & $\begin{array}{c}\text { sY1201 or } \\
\text { sY160 }\end{array}$ \\
\hline del. b2/b4 & + & + & + & - & - & - & + \\
\hline del. b2/b3 $3^{(\star)}$ & + & + & + & - & + & + & + \\
\hline del. gr/gr & + & + & + & + & - & + & + \\
\hline del. bl/b3 & + & _ & - & - & _ & + & + \\
\hline
\end{tabular}



Figure 1 Schematic representation of the proposed two step analysis for the detection of partial AZFc deletions. (A) the first step based on a PCR duplex with sY1 191/1291 (alternatively, with o1084/5 and o1276/7) shows the four different possible outcomes of the analysis: bl/b3, gr/gr, b2/ b3 (or u3-gr/gr or gl/g3), or absence of deletion; (B) the second step defines the breakpoints of the deletions.

Y chromosomes (hgrN). The three b2/b3 (gl/g3) deletions found in our study were observed in three different $\mathrm{Y}$ chromosome backgrounds (hgr J and DE in two oligospermic patients and $\mathrm{N} 3$ in a normospermic man). In previous studies, gr/gr deletions were found to occur on different $\mathrm{Y}$ chromosome backgrounds, in our cases on hgr P, J, DE, and $\mathrm{Y}^{*}$. The only normozoospermic man with this type of deletion (CS111) carries an hgrDE Y chromosome, which was also found in one severe oligozoospermic man (A234). However, these men have independent $\mathrm{gr} / \mathrm{gr}$ deletions; both are deleted for DAZ3/DAZ4 but subject CS111 has a deletion of CDY1b and subject A234 a deletion of CDYla.

\section{DISCUSSION}

Classical AZF deletions, defined by a few well designed markers ${ }^{20}$ are clinically relevant because a clear cause-effect relationship between these deletions and spermatogenic failure has been established. ${ }^{1}$ Owing to the absence of such deletions in normospermic men, the screening for AZF deletions has become part of the routine diagnostic investigation of the infertile male. The complete absence of the AZFa interval is associated with the most severe phenotype (complete absence of germ cells in the testis), whereas deletion of the entire $\mathrm{AZFb}$ region is associated with spermatogenic arrest (in general at the stage of primary spermatocytes). ${ }^{21}$ Deletion of the AZFc region can lead to different degrees of spermatogenic failure, with a significant variability between individuals, ranging from the absence of germ cells in the testis to the presence of spermatozoa in the ejaculate (oligospermia). These genotype-phenotype correlations refer to the three classical AZF deletions, and further data are needed to better define any clinically relevant difference between the so called classical AZFb (P5/proximal $\mathrm{Pl}$ ) and the two newly identified AZFb+C (P5/distal Pl and P4/distal P1) deletions. 
Table 1 Phenotype of patients and controls bearing $\mathrm{gr} / \mathrm{gr}$ and ${ }^{*} \mathrm{~b} 2 / \mathrm{b} 3$ deletions. The entire coding region of DAZL was sequenced, and no mutation was found except the single nucleotide polymorphism $A \rightarrow G$ transition in exon 2 (SNP 260). Patient A46 had undergone surgery at the age of 2 years for unilateral cryptorchidism

\begin{tabular}{|c|c|c|c|c|c|c|c|}
\hline \multirow[b]{2}{*}{ Code } & \multirow[b]{2}{*}{ Aetiology } & \multirow[b]{2}{*}{$\begin{array}{l}\text { DAZL (exons } \\
\text { from } 1 \text { to } 11 \text { ) }\end{array}$} & \multicolumn{2}{|c|}{$\begin{array}{l}\text { Deleted } \\
\text { gene copies }\end{array}$} & \multicolumn{3}{|c|}{ Semen parameters } \\
\hline & & & $D A Z$ & $C D Y$ & $\begin{array}{l}\text { Number } \\
\left(\mathrm{n} / \mathrm{ml}^{*} 10^{6}\right)\end{array}$ & $\begin{array}{l}\text { Motility } \\
\text { (A+B \%) }\end{array}$ & $\begin{array}{l}\text { Morphology } \\
(\%)\end{array}$ \\
\hline A49* & Idiopathic & No mutations & $3 / 4$ & $1 b$ & 0.38 & 10 & 13 \\
\hline A170 & Idiopathic & No mutations & $3 / 4$ & la & 0.9 & 20 & 16 \\
\hline A202 & Idiopathic & No mutations & $1 / 2$ & la & 10 & 30 & 13 \\
\hline A239 & Idiopathic & No mutations & $1 / 2$ & la & 4,2 & 14 & 16 \\
\hline A286 & Idiopathic & SNP 260 & $3 / 4$ & $1 b$ & 0.01 & - & - \\
\hline A $353^{*}$ & Idiopathic & No mutations & $3 / 4$ & la & 10 & 15 & 22 \\
\hline A 46 & Cryptorchidism sx & No mutations & $1 / 2$ & la & 0.01 & - & - \\
\hline A 184 & Varicocele sx & No mutations & $1 / 2$ & la & 0.6 & 0 & 2 \\
\hline A 234 & Varicocele sx & SNP 260 & $3 / 4$ & la & 0.7 & 3 & 8 \\
\hline $\operatorname{CS} 64^{*}$ & - & No mutations & $3 / 4$ & $1 b$ & 100 & 78 & 40 \\
\hline CS 111 & - & No mutations & $3 / 4$ & $1 b$ & 153 & 63 & 30 \\
\hline
\end{tabular}

In contrast to the situation for the complete AZFc deletion, genotype-phenotype correlations for the partial AZFc deletion seem to be more complicated. Using an STS +/approach $^{9}{ }^{10}$ we found two types of partial AZFc deletion, gr/gr and b2/b3 (u3-gr/gr or gl/g3) in our study population. Both deletion types were present in the normospermic group, indicating that these deletions, in contrast to b2/b4 deletions, are not specific for spermatogenic failure. The gr/gr deletion seems to be more frequent than b2/b3 (or u3-gr/gr) in our Italian cohort ( $73 \%$ of the deletions were gr/gr). The similar frequency of the $\mathrm{b} 2 / \mathrm{b} 3$ deletion in patients $(1.3 \%)$ and controls $(0.5 \%)$ does not support a pathogenic role for this

\section{A "gr/gr" deletion}

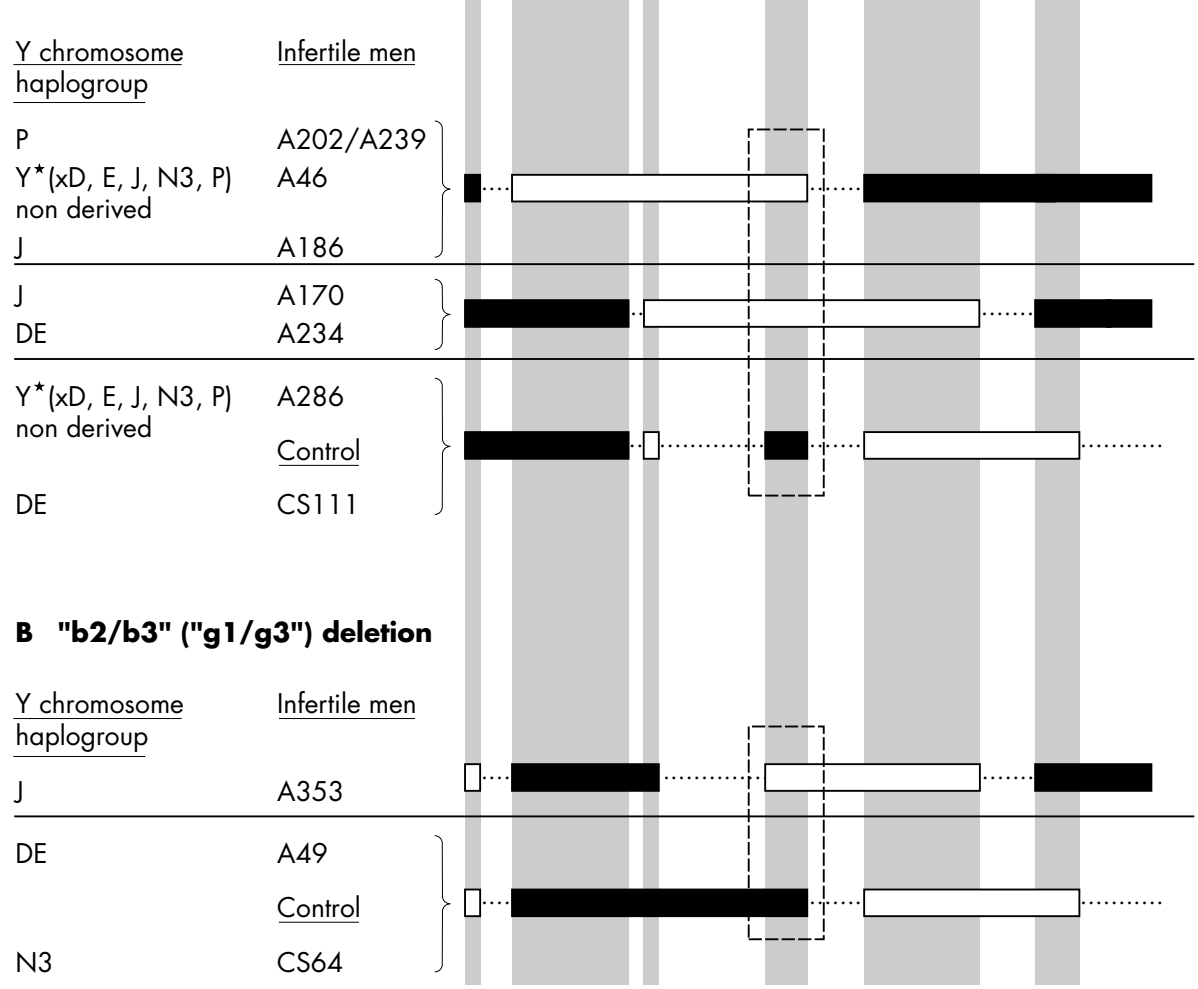

Figure 2 Schematic representation of the five distinct deletion patterns (based on the type of DAZ and CDY copies deleted) found in the 11 subjects with partial AZFc deletion. The gr/gr and b2/b3 (gl / g3) deletions were defined using a two step analysis based on STS +/ - described by Repping et $a^{\beta}$ and Machev et al. ${ }^{16}$ The orientation of the amplicons/sequences is not indicated because a number of possible inversion events may take place, leading to different deletion patterns. Open and filled boxes indicate the absence or presence of a given marker or gene, respectively. 
deletion; however, it has been found at high frequency in the general population of northern Europe in association with hgrN, indicating that hgrN may contain compensating $\mathrm{Y}$ linked factors. ${ }^{12}{ }^{13}$ Our normospermic man with b2/b3 (or u3gr/gr) deletion was hgrN3, whereas the two oligospermic men are hgrJ and hgrDE. Although the number is low, we can speculate that b2/b3 (u3-gr/gr; gl/g3) deletions are pathogenic only in association with certain haplogroups.

The frequency of gr/gr deletions was significantly higher in the infertile group with respect to controls, suggesting a possible deleterious effect of this polymorphism on spermatogenic efficiency. Similarly to the Repping study, ${ }^{9}$ the significant OR (10.1) indicates that gr/gr deletions can be considered as new risk factors for oligozoospermia. Although the mean sperm parameters (concentration, motility, and morphology) were not significantly different in the infertile group between men with gr/gr deletions and those without, there was a clear trend toward lower values in the former.

However, the most intriguing phenomenon observed in association with this type of deletion is the extreme heterogeneity of the phenotype, ranging from azoospermia to normozoospermia. In order to gain more insight into this phenomenon, we performed mutational analysis of $D A Z L$, an autosomal homologue of $D A Z$. DAZ was copied to the Y chromosome relatively recently, in the old world primate lineage, and is $90 \%$ identical to its autosomal ancestor DAZL. ${ }^{22}$

We found no new mutations in the entire coding region of $D A Z L$, and the polymorphic Thr12-Ala change (T12A) does not seem to have any modulating effect, probably because of its relatively high frequency in the normospermic group. However, as our mutational analysis was focused exclusively on the coding regions, we cannot exclude promoter variations that might affect the level of expression of DAZL.

Interestingly, deletion of the CDYIa copy was found only in the patient group, providing an even more significant difference $(p<0.003)$ between the infertile and normospermic group. A similar phenomenon has also been observed in another study population from Mediterranean France. ${ }^{13}$

The different combinations of loci found deleted in cases of partial AZFc deletion indicate that a number of possible inversion events must have preceded these deletions. ${ }^{8}{ }^{13}$ Clearly, the type of missing gene copies and the Y chromosome structure (hgr) on which the deletion arises are of fundamental importance for the understanding of a potential cause-effect relationship. Our data seem to support the hypothesis that $D A Z 1 / D A Z 2$ copies are functionally more important than $D A Z 3 / D A Z 4,{ }^{23}$ as the former were missing only in the patient group $(\mathrm{p}=0.037)$; however, a recent study found no difference in DAZI/DAZ2 deletion frequency between infertile men and fertile controls (with unknown sperm count), which appears to contradict this observation. ${ }^{13}$ On the other hand, our observation that deletion of CDYI is strongly associated with infertility is consistent with the findings of this same study. ${ }^{16}$ This now requires further confirmation.

Although it is clear that the STS $+/-$ analysis alone does not provide information about the type of missing gene copies and the hgr, we propose a flow chart (fig l) in order to carry out partial AZFc deletion analysis in a cost effective and relatively simple manner. At this point, it is difficult to decide whether routine screening for partial AZFc deletions will be worthwhile. Clearly, gr/gr deletions, especially those resulting in the loss of CDYla, can be considered a risk factor. However, the ideal situation would be to define a genetic profile specific for spermatogenic failure, although this may not exist.

Future studies in larger, well selected groups of subjects (patients without interfering abnormal andrological findings and normospermic controls) should focus on the combined definition of the type and copy number of the AZFc genes deleted in men with partial deletions and the haplogroup of the $\mathrm{Y}$ chromosome. This will probably provide a means of distinguishing between pathogenic and neutral (or compensated by other Y factors) deletion types. If we consider that, together with the gr/gr deletion, other $\mathrm{Y}$ related factors (protective or negative) will be transmitted to the male offspring, we can eventually propose screening for partial AZFC deletion prior to assisted reproductive techniques. However, until a clear definition of pathogenic and nonpathogenic deletions is established, the prediction of the testicular phenotype of the offspring will remain rather vague.

\section{ACKNOWLEDGEMENTS}

We are grateful to Dr M Rotondi for his valuable contribution to the statistical analysis of our data. We thank the clinical staff of the Andrology Unit and Reproductive Physiology for patient's recruitment: Professor M Maggi, Dr G Corona, Dr M Magini, Dr L Petrone, Dr A Cilotti, Professor E Coccia, Professor I Noci. The study was supported by a grant from the University of Florence.

\section{Authors' affiliations}

C Giachini, E Guarducci, S Degl'Innocenti, L Becherini, G Forti, C Krausz, Andrology Unit, Department of Clinical Physiopathology, Center for Research, Transfer and Higher Education on Chronic, Inflammatory, Degenerative and Neoplastic Disorders, University of Florence, Viale Pieraccini, 6, Florence 50139, Italy

G Longepied, M J Mitchell, Inserm U.491, Faculté de médecine, 13385 Marseille, France; Institut de Médecine de la Reproduction, 13008 Marseille, France

Competing interests: none declared

The first two authors have contributed equally to the study and they should be regarded as joint first authors.

Correspondence to: Dr C Krausz, Andrology Unit, Viale Pieraccini, 6 , Florence, 50139, Italy; c.krausz@dfc.unifi.it

Received 13 October 2004

Revised 29 November 2004

Accepted 1 December 2004

\section{REFERENCES}

1 Krausz C, Forti G, McElreavey K. The Y chromosome and male fertility and infertility. Int J Androl 2003;26:70-5.

2 Tiepolo L, Zuffardi O. Localization of factors controlling spermatogenesis in the non fluorescent portion of the human Y chromosome long arm. Hum Genet 1976:34:119-24.

3 Vogt PH, Edelmann A, Kirsch S, Henegariu O, Hirschmann P, Kiesewetter F, Kohn FM, Schill WB, Farah S, Ramos C, Hartmann M, Hartschuh W, Meschede D, Behre HM, Castel A, Nieschlag E, Weidner W, Grone HJ, Jung A, Engel W, Haidl G. Human chromosome azoospermia factors (AZF) mapped to different subregions in Yq11. Hum Mol Genet 1996;5:933-43.

4 Kuroda-Kawaguchi T, Skaletsky H, Brown LG, Minx PJ, Cordum HS, Waterston RH, Wilson RK, Silber S, Oates R, Rozen S, Page DC. The AZFc region of the $Y$ chromosome features massive palindromes and uniform recurrent deletions in infertile men. Nat Genet 2001;29:279286.

5 Repping S, Skaletsky H, Lange J, Silber S, Van der Veen F, Oates RD, Page DC, Rozen S. Recombination between palindromes P 5 and P1 on the human $Y$ chromosome causes massive deletions and spermatogenic failure. Am J Hum Genet 2002;71:906-22.

6 Skaletsky H, Kuroda-Kawaguchi T, Minx PJ, Cordum HS, Hillier L, Brown LG, Repping S, Pyntikova T, Ali J, Bieri T, Chinwalla A, Delehaunty A, Delehaunty K, Du H, Fewell G, Fulton L, Fulton R, Graves T, Hou SF, Latrielle P, Leonard S, Mardis E, Maupin R, McPherson J, Miner T, Nash W, Nguyen C, Ozersky P, Pepin K, Rock S, Rohlfing T, Scott K, Schultz B, Strong C, TinWollam A, Yang SP, Waterston RH, Wilson RK, Rozen S, Page DC. The malespecific region of the human $Y$ chromosome is a mosaic of discrete sequence classes. Nature 2003;423:825-37.

7 Yen P. The fragility of fertility. Nat Genet $2001 ; 29: 243-4$

8 Vogt PH. Genomic heterogeneity and instability of the AZF locus on the human Y chromosome. Mol Cell Endocrinol 2004;224:1-9.

9 Repping S, Skaletsky H, Brown L, Van Daalen SK, Korver CM, Pyntikova T, Kuroda-Kawaguchi T, De Vries JW, Oates RD, Silber S, Van der Veen F, Page DC, Rozen S. Polymorphism for a 1.6-Mb deletion of the human $Y$ chromosome persists through balance between recurrent mutation and haploid selection. Nat Genet 2003;35:247-51. 
10 Repping S, Korver CM, Oates RD, Silber S, Van der Veen F, Page DC, Rozen S. Are sequence family variants useful for identifying deletions in the human Y chromosome? Am J Hum Genet 2004;75:514-17.

11 Reijo RA, Lee TY, Salo P, Alagappan R, Brown LG, Rosenberg M, Rozen S, Jaffe T, Straus D, Hovatta O, De la Chapelle A, Silber S, Page DC. Diverse spermatogenetic defects in humans caused by $Y$ chromosome deletions encompassing a novel RNA-binding protein gene. Nat Genet 1995; 10:383-93.

12 Repping S, Van Daalen SK, Korver CM, Brown LG, Marszalek JD, Gianotten J Oates RD, Silber S, Van der Veen F, Page DC, Rozen S. A family of human Y chromosomes has dispersed throughout northern Eurasia despite a $1.8-\mathrm{Mb}$ deletion in the azoospermia factor c region. Genomics 2004;83:1046-52.

13 Machev N, Saut N, Longepied G, Terriou P, Navarro A, Levy N, Guichaoua M, Metzler-Guillemain C, Collignon P, Frances A-M, Belougne J, Clemente E, Chiaroni J, Chevillard C. Durand C, Ducourneau A, Pech N, McElreavey K, Mattei M-G, Mitchell MJ. Sequence family variant loss from the AZFc interval of the human $Y$ chromosome, but not gene copy loss, is strongly associated with male infertility. J Med Genet 2004;41:814-25.

14 Fernandes S, Paracchini S, Meyer LH, Floridia G, Tyler-Smith C, Vogt PH. A large AZFc deletion removes DAZ3/DAZ4 and nearby genes from men in $Y$ haplogroup N. Am J Hum Genet 2004;74:180-7.

15 Yen PH. Putative biological functions of the DAZ family. Int J Androl 2004;27:125-9.

16 Slee R, Grimes B, Speed RM, Taggart M, Maguire SM, Ross A, McGill NI, Saunders PT, Cooke HJ, A human DAZ transgene confers partial rescue of the mouse Dazl null phenotype. Proc Natl Acad Sci U S A 1999;96:8040-5.

17 Rosser ZH, Zerjal T, Hurles ME, Adojaan M, Alavantic D, Amorim A, Amos W, Armenteros M, Arroyo E, Barbujani G, Beckman G, Beckman L, Bertranpetit J, Bosch E, Bradley DG, Brede G, Cooper G, Corte-Real HB, De Knijff P, Decorte R, Dubrova YE, Evgrafov O, Gilissen A, Glisic S, Golge M, Hill EW, Jeziorowska A, Kalaydjieva L, Kayser M, Kivisild T, Kravchenko SA,
Krumina A, Kucinskas V, Lavinha J, Livshits LA, Malaspina P, Maria S, McElreavey K, Meitinger TA, Mikelsaar AV, Mitchell RJ, Nafa K, Nicholson J, Norby S, Pandya A, Parik J, Patsalis PC, Pereira L, Peterlin B, Pielberg G, Prata MJ, Previdere C, Roewer L, Rootsi S, Rubinsztein DC, Saillard J, Santos FR, Stefanescu G, Sykes BC, Tolun A, Villems R, Tyler-Smith C, Jobling MA. Y-chromosomal diversity in Europe is clinal and influenced primarily by geography, rather than by language. Am J Hum Genet 2000;67:1526-43

18 Zerial T, Dashnyam B, Pandya A, Kayser M, Roewer L, Santos FR, Schiefenhovel W, Fretwell $N$, Jobling MA, Harihara S, Shimizu $K$ Semiidmaa D, Sajantila A, Salo P, Crawford MH, Ginter EK, Evgrafov OV, Tyler-Smith C. Genetic relationships of Asians and Northern Europeans, revealed by Y-chromosomal DNA analysis. Am J Hum Genet 1997:60:1174-83.

19 Becherini L, Guarducci E, Degl'Innocenti S, Rotondi M, Forti G, Krausz C. DAZL polymorphisms and susceptibility to spermatogenic failure: an example of remarkable ethnic differences. Int J Androl 2004;27:375-81.

20 Simoni M, Bakker E, Krausz C. EAA/EMQN best practice guidelines for molecular diagnosis of Y-chromosomal microdeletions. State of the Art 2004. Int J Androl 2004;27:240-9.

21 Krausz C, Quintana-Murci L, McElreavey K. Prognostic value of Y deletion analysis: what is the clinical prognostic value of $Y$ chromosome microdeletion analysis? Hum Reprod 2000;15:1431-4.

22 Saxena R, Brown LG, Hawkins T, Alagappan RK, Skaletsky H, Reeve MP, Reijo R, Rozen S, Dinulos MB, Disteche CM, Page DC. The DAZ gene cluster on the human $Y$ chromosome arose from an autosomal gene that was transposed, repeatedly amplified and pruned. Nat Genet 1996;14:292-9.

23 Fernandes S, Huellen K, Goncalves J, Dukal H, Zeisler J, Rajpert De Meyts E, Skakkebaek NE, Habermann B, Krause W, Sousa M, Barros A, Vogt PH. High frequency of DAZ1/DAZ2 gene deletions in patients with severe oligozoospermia. Mol Hum Reprod 2002;8:286-98.

\section{CORRECTION}

doi: 10.1136/jmg.2004.23960corrl

The Letter to JMG titled, Ancestral RET haplotype associated with Hirschsprung's disease shows linkage disequilibrium at - 1249 ( $J$ Med Genet 2005;42:322-27) should have been published as a short report and the following abstract was omitted:

Background: Hirschsprung disease (HSCR) is a complex disorder with traditional germline mutations in RET in up to $30 \%$ of familial cases and in 3\% of sporadic cases in a population-based series. We have previously demonstrated that an ancestral haplotype at the 5' end of RET (haplotype 0) was strongly associated with a large subset of isolated HSCR cases and that a putative low penetrance susceptibility locus was encompassed within this ancestral haplotype, anchored by exon 2 SNP A45A.

Objective: To determine the $5^{\prime}$ extent of the HSCR-associated ancestral haplotype by defining the linkage disequilibrium breakpoint in search for the low penetrance susceptibility locus.

Methods: Systematic screening of the region upstream of the anchoring A45A SNP, comprising RET intron 1 , exon 1 , and promoter in 117 population-based HSCR cases and 100 controls. Dual luciferase assay to determine differential activities between SNP combinations near a transcription start site.

Results: New SNP's were found which formed upstream haplotypes, anchored by A45A, in linkage disequilibrium with HSCR $\left(\chi^{2}=76.96, p<0.00000001\right)$. Linkage disequilibrium appeared to break at the $-1249 \mathrm{C} / \mathrm{T}$ SNP. Further, the HSCR-associated genotype (00) was found in $>60 \%$ of HSCR but only $2 \%$ of controls. Because only 2 variants, $-200 A>G$ and $-196 C>A$, lie within the promoter region and are in proximity to the transcriptional start site (at -195), we modelled these combinations into constructs for luciferase reporter assay. The HSCRassociated SNP combination showed the lowest activity and the control-associated combination, the highest.

Conclusions: Our observations seem to discard the existence of a HSCR-causing mutation as it is conceived in the traditional sense, but strengthen the idea of a specific combination of variants conferring susceptibility to the disease in a low penetrance fashion. The data derived from our functional "in vitro" studies would suggest that the HSCR-associated haplotype 0 may result in a lower level of expression of the RET gene.

The journal apologises for this error. 